Article

\title{
Improving the Bearing Strength of Sandy Loam Soil Compressed Earth Block Bricks Using Sugercane Bagasse Ash
}

\author{
Ramadhan W. Salim, Julius M. Ndambuki and David A. Adedokun * \\ Department of Civil Engineering, Tshwane University of Technology, Pretoria 0001, South Africa; \\ E-Mails: SalimRW@tut.ac.za (R.W.S.); Ndambuki@tut.ac.za (J.M.N.) \\ * Author to whom correspondence should be addressed; E-Mail: AdedokunDA@tut.ac.za; \\ Tel.:+27-738-205-877.
}

Received: 24 March 2014; in revised form: 19 May 2014 / Accepted: 20 May 2014 /

Published: 10 June 2014

\begin{abstract}
The need for affordable and sustainable alternative construction materials to cement in developing countries cannot be underemphasized. Compressed Earth Bricks have gained acceptability as an affordable and sustainable construction material. There is however a need to boost its bearing capacity. Previous research show that Sugarcane Bagasse Ash as a soil stabilizer has yielded positive results. However, there is limited research on its effect on the mechanical property of Compressed Earth Brick. This current research investigated the effect of adding 3\%, 5\%, 8\% and 10\% Sugarcane Bagasse Ash on the compressive strength of compressed earth brick. The result showed improvement in its compressive strength by $65 \%$ with the addition of $10 \%$ Sugarcane Bagasse Ash.
\end{abstract}

Keywords: sugarcane bagasse ash; compressive strength; stabilization

\section{Introduction}

The need for affordable and sustainable housing cannot be under emphasized, especially in the developing nations. According to the 1999 national population and housing census in Kenya [1] (p. 680), there are between three and six million people in urban and rural areas respectively in need of proper housing. For an average of four persons per household, there are about 750,000 and 1,500,000 households in urban and rural areas respectively in need of proper housing [1] (p. 680). In recent years, the potential for earth as a valuable and desirable construction material has been rediscovered. Methods derived 
from traditional techniques are being developed to improve the quality of earth construction and broaden the potential of its application [2].

The Compressed Earth Brick (CEB) has over the years gained acceptability for construction of buildings in developing countries. It involves the use of wooden tamps (as was the case when the concept of Compressed Earth Brick emerged) or the application of modern sophisticated mechanical presses to compress earth, forming the bricks [3] (p. 6). Its advantages lie in its sustainability and environmental friendliness; as it has a very low embodied energy [4] (p. 140) and the technology is affordable. The desire to further improve the quality and performance of the Compressed Earth Brick at low cost led to the modern day phenomenon of stabilization.

Soil stabilization involves the treatment of soils in order to improve their engineering properties such that they become more suitable for construction [5] (pp. 4-6). The Department of the Army in Washington [6] (p. 9.1) classified the methods of soil stabilization as Mechanical and Chemical Admixture. The objective of mechanical stabilization is to blend available soils so that, when properly compacted, they give the desired stability. The technique includes: compaction of the soil, alteration of the particle size distribution and drying of the soil. Compaction has the effect of increasing the density and strength of the soil, and reducing its permeability. Chemical Admixture stabilization relies on the use of an admixture to alter the chemical properties of the soil to achieve the desired effect. These admixtures are referred to as stabilizers.

The Housing and Building Research Institute (HABRI) [7] identifies various stabilizers such as lime, cement, murram soil, rice husk ash, sand, bitumen, cow dung, fibrous type and bagasse ash. HABRI in 1997 undertook a research on the viability of Rice Husk Ash (RHA) as a supplement for Ordinary Portland Cement (OPC) and Lime for the stabilization of soil bricks and came up with a conclusion that RHA can replace 50\% OPC without losing strength [8] (p. 7). The choice of the stabilizer to be employed in the stabilization of soil is dependent on the type of soil to be stabilized, the purpose for which the stabilized layer will be used, the type of soil quality improvement desired, the required strength and durability of the stabilized layer and cost and environmental conditions [6] (pp. 9.1-9.3).

Sugarcane bagasse is a solid "waste" material which is generated as a by-product from boilers of sugar and alcohol factories who use sugarcane as raw material. These industries produce large amounts of Sugarcane Bagasse Ash which is composed mainly of sugar, fibrous material and water. Sugarcane Bagasse Ash is considered as waste because it is not bio-gradable [9] (p. 7), and hence poses a detrimental effect on the environment. Many developing countries produce large amount of Sugarcane Bagasse Ash with limited recycling for soil amendment. For instance, the total Sugarcane Bagasse Ash generation in Kenya is estimated to be about 1.6 million tons per year with a potential of about 2.6 million tonnes out of which only $25 \%$ is recycled by the factories as a renewable energy [10] (p. 479). Larger percentage of it is disposed to open landfills [11] (p. 218).

Sugarcane Bagasse Ash mainly contains silica [12] (p. 410). Sugarcane Bagasse Ash is known to have a pozzolan property which poses economic advantages and environmental enhancing potentials [13] (p. 3). Over the years, Sugarcane Bagasse Ash has gained acceptability in the construction industry with much emphasis on its performance as a supplementary material in concrete. Previous researches carried out on partial replacement of cement with Sugarcane Bagasse Ash showed that Sugarcane Bagasse Ash had positive effect on the strength and durability of concrete [14,15]. 
With success recorded in the use of Sugarcane Bagasse Ash in concrete, researchers have been conducting research on the suitability of Sugarcane Bagasse Ash in the stabilization of soil. In Nigeria, Onyelowe [16] observed an increase in the bearing properties of lateritic soil with an increase in sugarcane bagasse ash. This was also supported by Alavez- Ramirez et al. [17], who concluded that an addition of $10 \%$ lime and 10\% Sugarcane Bagasse Ash significantly improves the durability and mechanical properties of compacted soil bricks. The use of Sugarcane Bagasse Ash as fertilizer [18] also suggests that compressed soil stabilized with Sugarcane Bagasse Ash can still find application in agriculture after demolition. In Kenya, the application of Sugarcane Bagasse Ash to stabilize compressed soil is yet to be explored.

The aim of this research was to study the effect of Sugarcane Bagasse Ash stabilization on the compressive strength of compacted sandy loam bricks as an alternative to existing Sugarcane Bagasse Ash waste disposal and provision of more durable low-cost bricks for housing in Kenya.

\section{Materials and Methods}

Sandy loam soil used in this research was obtained in Eldoret area of western Kenya after which the determination of its particle size distribution was performed using the wet sieve method recommended by British Standard 1377 [19]. The optimum water content and maximum dry density of the soil was also obtained by proctor compaction test. Sugarcane Bagasse Ash samples were obtained from the Lubao Jagerry sugar factory in Kakamega district, Western province of Kenya. Details of the chemical composition are presented in Table 1.

Table 1. Chemical composition of bagasse ash.

\begin{tabular}{cc}
\hline Mineral & Percentage (\%) \\
\hline $\mathrm{SiO}_{2}$ & 73 \\
$\mathrm{Al}_{2} \mathrm{O}_{3}$ & 6.7 \\
$\mathrm{Fe}_{2} \mathrm{O}_{3}$ & 6.3 \\
$\mathrm{CaO}$ & 2.8 \\
$\mathrm{MgO}$ & 3.2 \\
$\mathrm{P}_{2} \mathrm{O}_{5}$ & 4.0 \\
$\mathrm{Na}_{2} \mathrm{O}$ & 1.1 \\
$\mathrm{~K}_{2} \mathrm{O}$ & 2.4 \\
Loss of Ignition & 0.9 \\
\hline
\end{tabular}

\subsection{Mixture Proportion and Sample Preparation}

Soil preparation for the brick making process involved sieving the soil through the $2.0 \mathrm{~mm}$ sieve. Six (6) Kg weight of soil and bagasse ash percentages by weight (see Table 2) were measured and homogeneously mixed by hand. The choice of the mixing method was dictated by need for low cost considerations. The mixing process lasted for $10 \mathrm{~min}$ to ensure an even distribution of ash in the mixture. Water content up to the optimum moisture content was gradually added to the mix of soil and bagasse ash. Additional 1\% water beyond the optimum moisture content was added afterwards to allow for the hydration of bagasse ash according to American Concrete Institute [20]. After the mixing process, the soil/bagasse mixes were poured into a steel mold with dimension $285 \mathrm{~mm} \times 145 \mathrm{~mm} \times 95 \mathrm{~mm}$, 
after which they were pressed using a manual press with the following characteristics; Lever arm: $1800 \mathrm{~mm}$, internal dimension of the mold: $300 \mathrm{~mm} \times 150 \mathrm{~mm} \times 100 \mathrm{~m}$, applied force : 1 Kilonewton $(\mathrm{KN})$, compression mode: static. Curing was done under mulching using bagasse fibers for one week and was thereafter air dried until the test dates (see Figure 1).

Table 2. Mix ratio of brick.

\begin{tabular}{cccc}
\hline Sugar bagasse ash (\%) & Soil & SCBA & Water \\
\hline 0 & 6.0 & - & 2.04 \\
3 & 6.0 & 0.18 & 2.04 \\
5 & 6.0 & 0.3 & 2.04 \\
8 & 6.0 & 0.48 & 2.04 \\
10 & 6.0 & 0.6 & 2.04 \\
\hline
\end{tabular}

SCBA: Sugarcane Bagasse.

Figure 1. Curing setup in the laboratory.

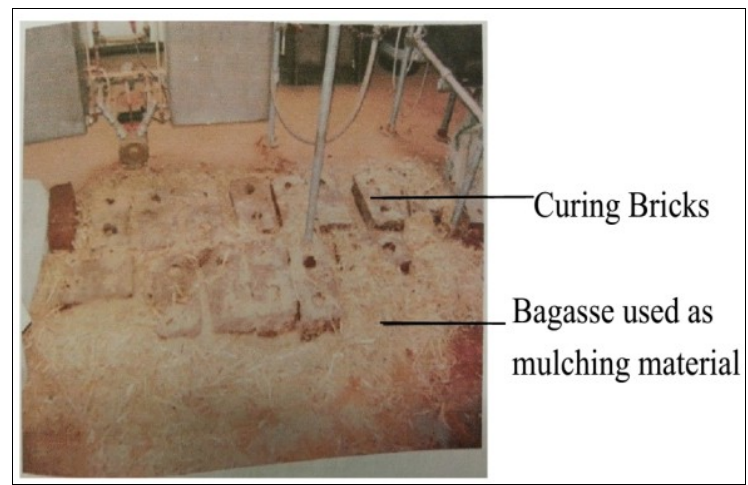

\subsection{Compressive Strength Test}

The dry compressive strength test of the brick was done in accordance with the Kenyan Bureau of Standard KS02-1070 [21]. The tests were carried out after 14, 21 and 28 days of molding the bricks. The compressive strength of the block for each day of testing was obtained by taking an average of the compressive strength of 3 block samples. The compressive strength set up is shown in Figure 2.

Figure 2. Compression test set up.

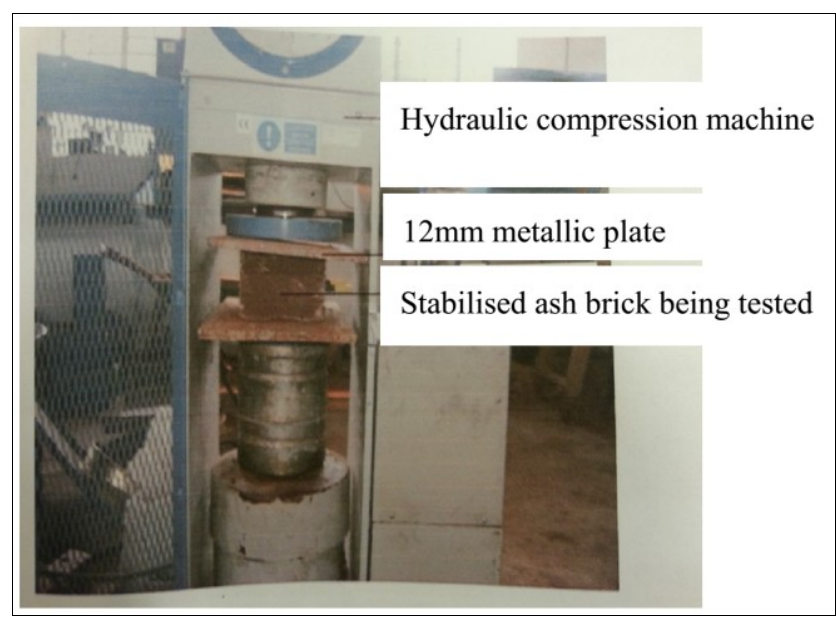




\subsection{Shrinkage Cracks}

The failure crack pattern after the compressive strength test was measured using the crack meter shown in Figure 3. The cracks in the Compressed Earth Brick were measured after 28 days of curing. The requirement for shrinkage crack limits as specified by KS02-1070 [21] states that cracks should not be more than $0.5 \mathrm{~mm}$ wide and should not exceed $50 \%$ in length of the blocks in the direction parallel to the crack. It further states that where the cracks are not parallel, the projected length shall be measured.

Figure 3. Crack meter.

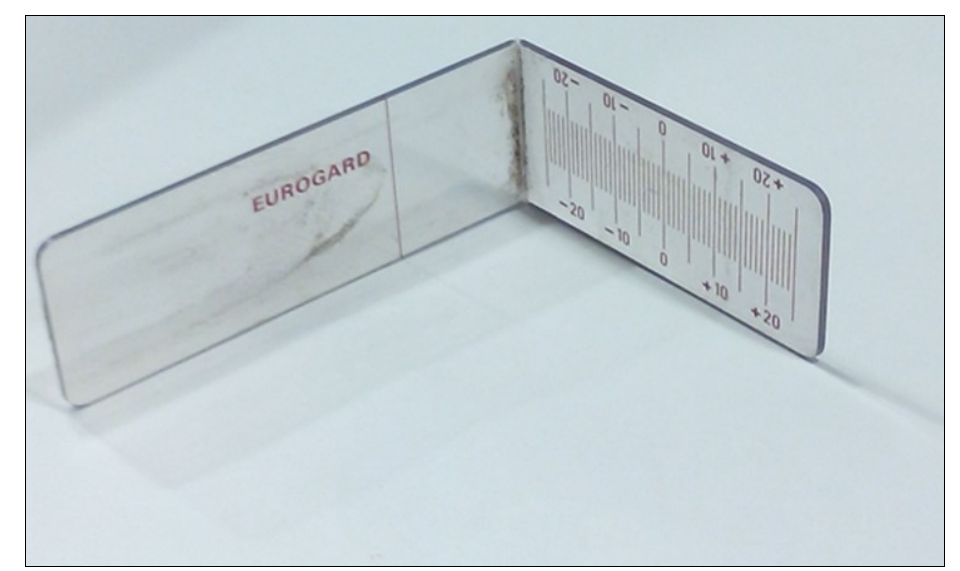

\section{Results and Discussions}

\subsection{Soil Characteristics}

Figure 4 shows the particle size distribution of the soil used. It can be seen that $0.5 \%$ of the soil passed through the $75 \mu \mathrm{m}$ (No. 200) sieve while $99.5 \%$ of the soil sample was retained. $100 \%$ of the sample passed through the $4.75 \mathrm{~mm}$ (No. 4) sieve. From Figure 2, the coefficient of uniformity $\left(\mathrm{C}_{\mathrm{u}}\right)$ is 2.75 while the coefficient of curvature $\left(\mathrm{C}_{c}\right)$ is 1.11 . These properties of the soil shows that it is a coarse-grained soil which is poorly graded (SP) based on the unified Soil Classification chart [22].

Figure 4. Particle size distribution curve for soil.

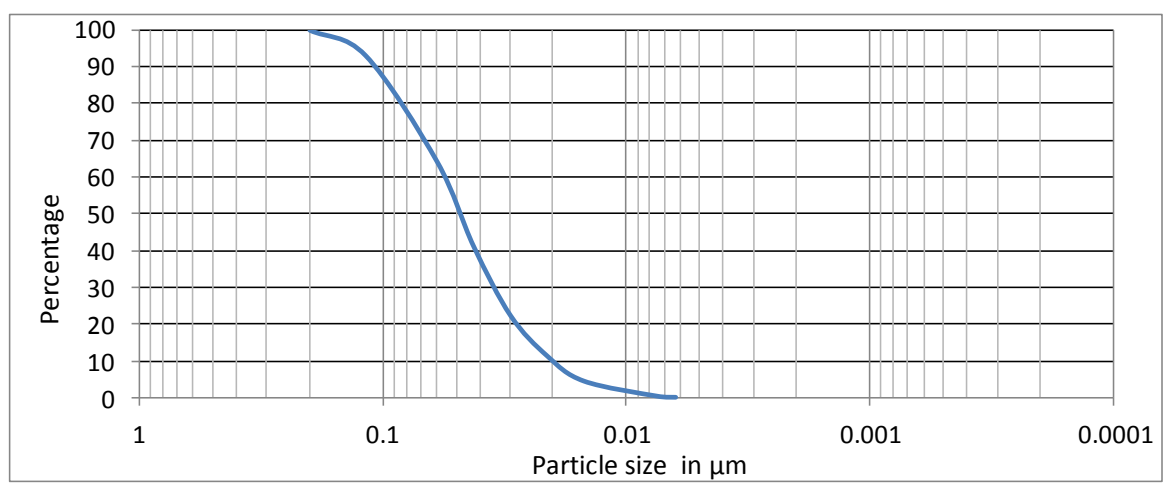

Figure 5 shows the result of the standard proctor test carried out which indicates an optimum water content of $31.30 \%$ and a dry density of $1221 \mathrm{~kg} / \mathrm{m}^{3}$. 
Figure 5. Standard proctor test.

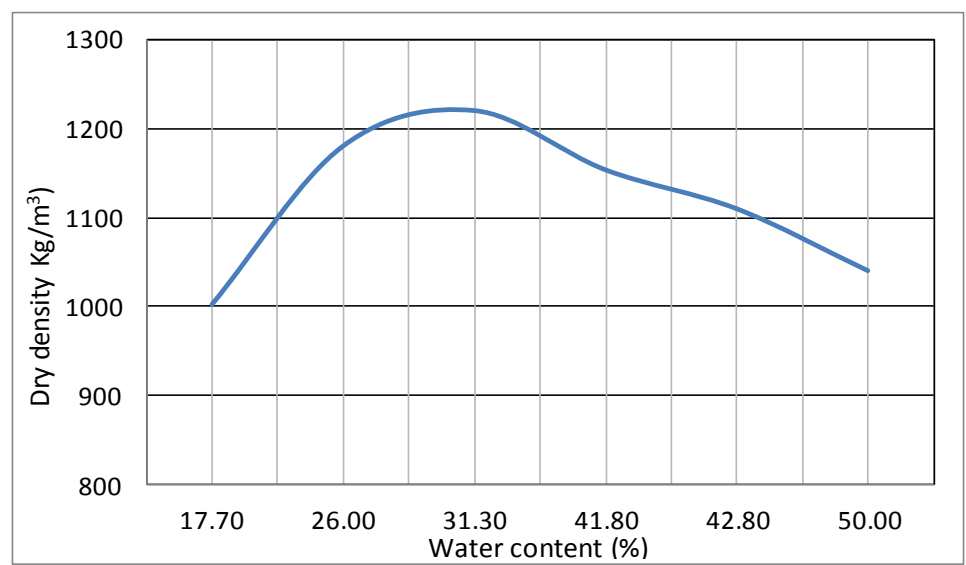

\subsection{Compressive Strength}

The results of the compressive strength carried out on the brick at different percentage bagasse ash stabilization are presented in Figure 6. This showed that the compressive strength of the Sugarcane Bagasse Ash stabilized Compressed Earth Brick increased with an increase sugarcane bagasse ash. The Kenya Standard Specification [21] specifies that at 28 days, the dry compressive strength of Compressed Earth Block must be greater than $2.5 \mathrm{Mpa}$. It can be seen that the control sample was less than the specification at 28 days while the $3 \%, 5 \%, 8 \%$ and $10 \%$ samples met the requirement of the standard. The compressive strength increased with the Sugarcane Bagasse Ash content such that a 10\% Sugarcane Bagasse Ash stabilization increased the compressive strength by $65 \%$. This could be attributed to the progressive densification of the soil/Sugarcane Bagasse Ash matrix as a result of hydration and pozzolanic reactions [17] (pp. 296-305).

Figure 6. Plot of compressive strength of compressed earth brick at different \% Sugarcane Bagasse Ash stabilization.

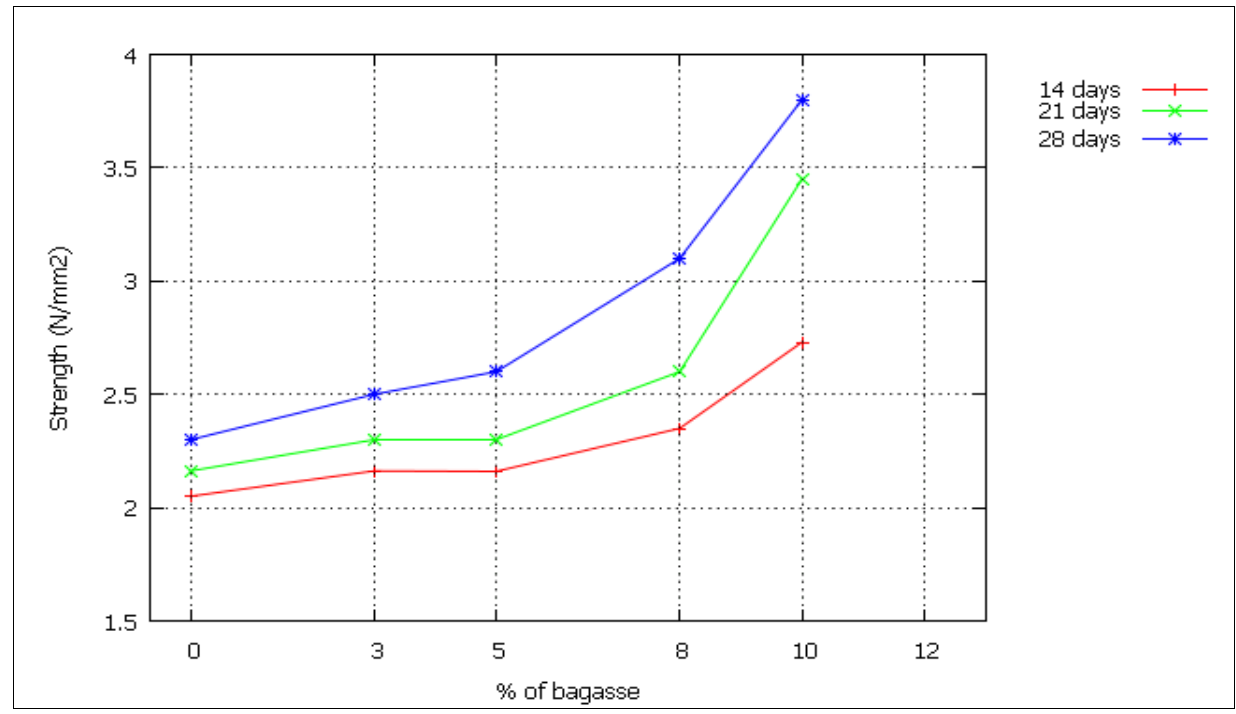

Also, as shown in Figure 7, compressive strength of the Compressed Earth Bricks stabilized with Sugarcane Bagasse Ash increased with an increase in curing age at a higher rate than the control 
sample. The control compressed earth brick had a compressive strength of $2.050 \mathrm{Mpa}$ after 14 days of curing; between 14 to 21 days, there was an increase in compressive strength of $5.5 \%$ and a further increase in compressive strength of $6.7 \%$ between 21 and 28 days of curing.

The 3\% and 5\% Sugarcane Bagasse Ash stabilized compressed earth brick showed a similar compressive strength development at 14 days of 2.162 and 2.160 Mpa respectively. Between 14 and 21 days, the 3\% Sugarcane Bagasse Ash stabilized compressed earth brick recorded an increase in strength of $6.4 \%$ while the $5 \%$ Sugarcane Bagasse Ash stabilized compressed earth brick recorded an increase of $6.5 \%$.

Figure 7. Plot of compressive strength of Sugarcane Bagasse Ash stabilized compressed earth brick at different curing ages.

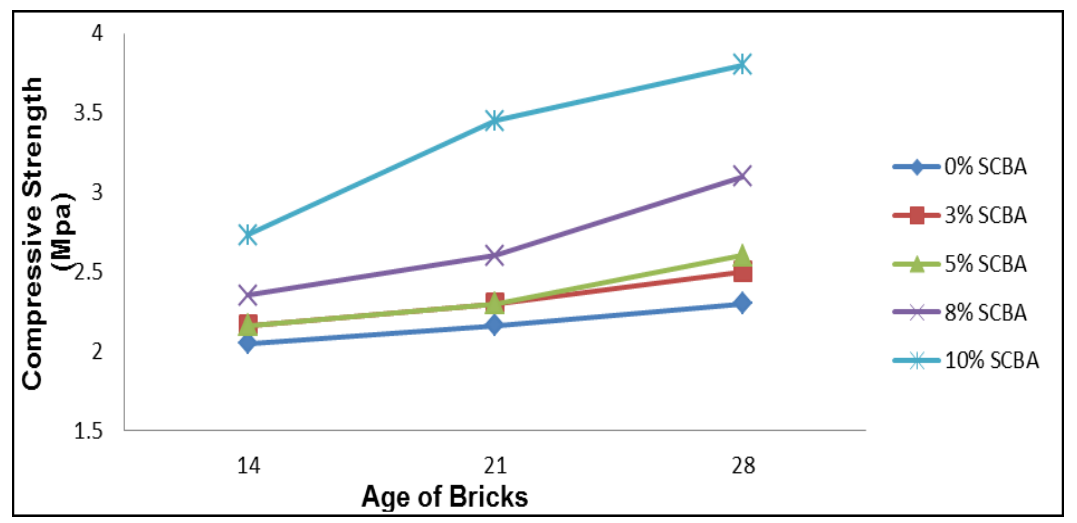

However, between 21 to 28 days curing, the 3\% Sugarcane Bagasse Ash stabilized compressed earth brick had a lesser compressive strength growth than the 5\% Sugarcane Bagasse Ash stabilized compressed earth brick of 9.3\% and 13.9\% respectively. The 10\% Sugarcane Bagasse Ash stabilized compressed earth brick gained the highest compressive strength within the first 14 days with a value of $2.730 \mathrm{Mpa}$ and a compressive strength growth rate of $26.4 \%$ between 14 and 21 days. Between 21 and 28 days, there was a drop in the compressive strength growth rate which increased by $12.8 \%$. Figure 8 shows the variation in compressive strength gain rate between 14 to 21 days and 21 to 28 days.

Figure 8. Percentage change in compressive strength of Sugarcane Bagasse Ash stabilized compressed earth brick between 14 to 21 days and 21 to 28 days.

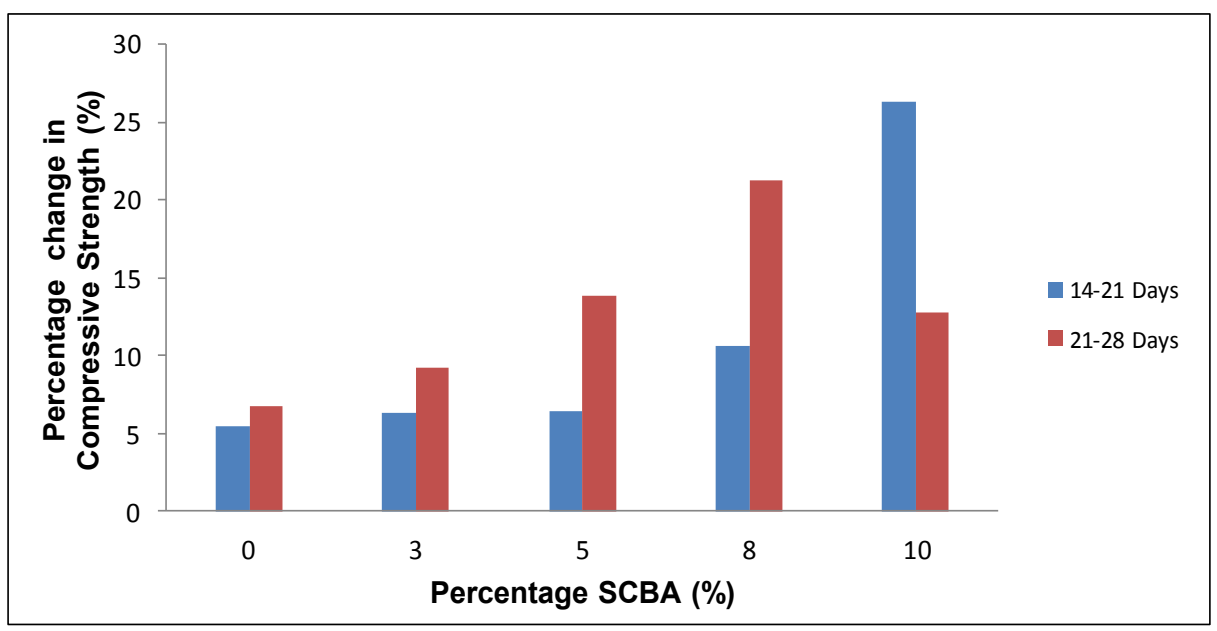


This implies that for the control, 3\%, 5\% and 8\% Sugarcane Bagasse Ash stabilized compressed earth brick, change in compressive strength between the 21st and 28th day was higher and largely contributed to the compressive strength of the bricks at 28 days while for the $10 \%$ Sugarcane Bagasse Ash stabilized compressed earth brick, the change in compressive strength between the 14th and 21st day was higher and largely contributed to the compressive strength of the bricks at 28 days.

\subsection{Failure Pattern}

During the compressive strength tests, there were two types of failures noticed. The stabilized bricks exhibited a compressive type failure as the brick did not disintegrate completely. This is similar to concrete failure pattern. This is shown by Figure 9.

Figure 9. Failure pattern of SCBA stabilized earth brick.

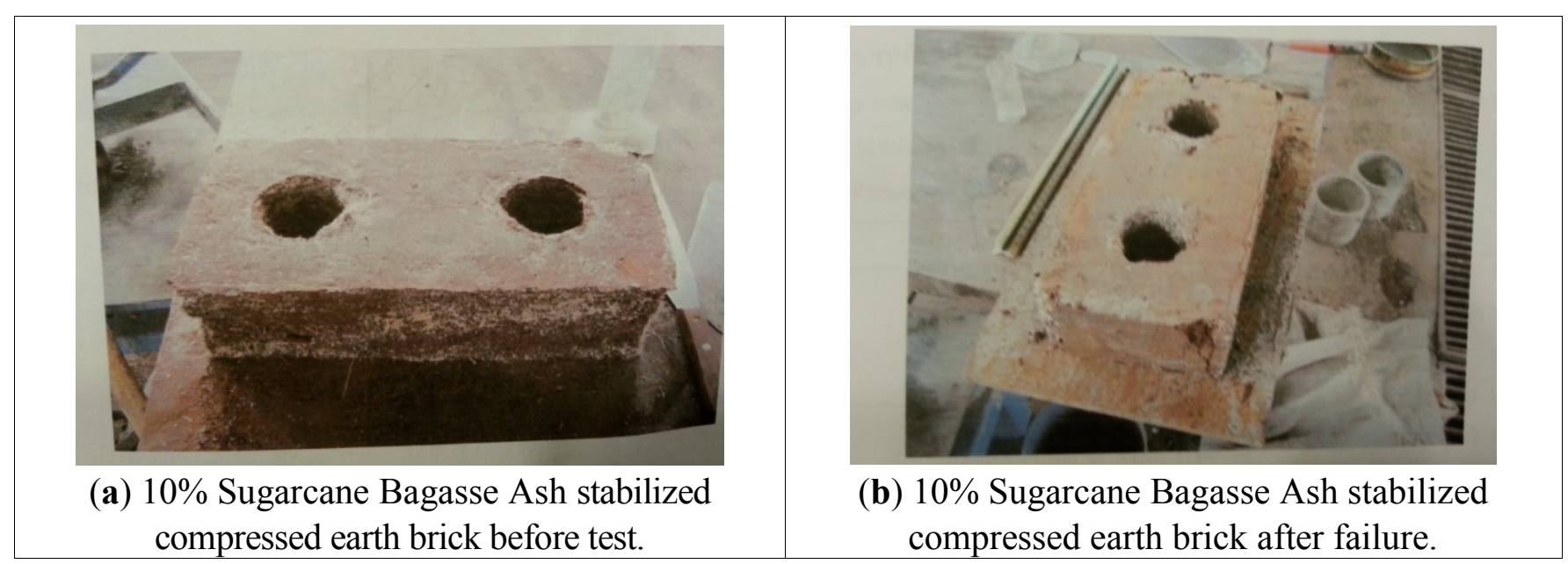

The un-stabilized bricks exhibited a creep like failure. The bricks disintegrated to small pieces which started from the started from the edges as shown in Figure 10.

Figure 10. Failure pattern of SCBA un-stabilized earth brick.

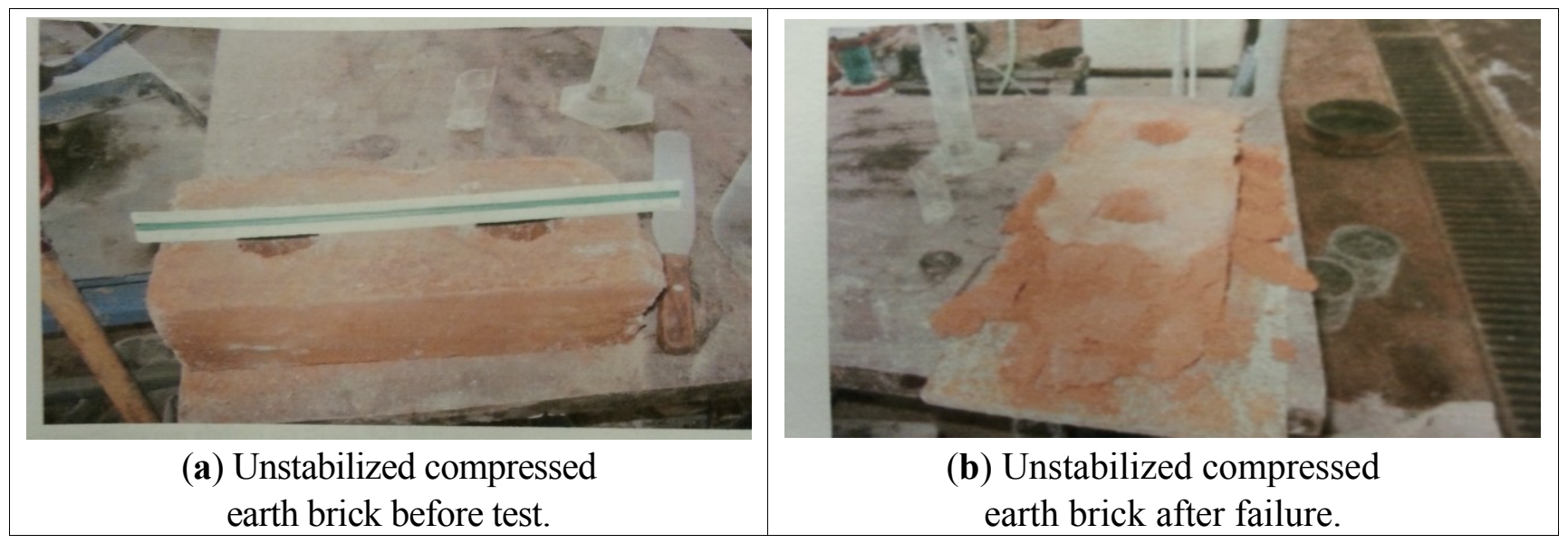




\subsection{Shrinkage Cracks}

Table 3 shows the shrinkage cracks that were developed in the samples after 28 days of casting.

Table 3. Length of crack in direction parallel to cracks.

\begin{tabular}{cc}
\hline Sugarcane Bagasse Ash (\%) & \% Length of crack in direction parallel to cracks \\
\hline 0 & 30 \\
3 & 30 \\
5 & 20 \\
8 & 25 \\
10 & 23 \\
\hline
\end{tabular}

The shrinkage test also showed that the five samples had a crack width less than $0.3 \mathrm{~mm}$ which conforms to KS02-1070 [21] that recommends a shrinkage crack less than $0.5 \mathrm{~mm}$ wide. The standard also recommends that the shrinkage crack must be less than $50 \%$ of the parallel block dimension. The un-stabilized compressed earth brick and 3\% Sugarcane Bagasse Ash stabilized compressed earth brick had a crack of $30 \%$ of the parallel block dimension. For the 5\%,8\% and 10\% Sugarcane Bagasse Ash stabilized compressed earth brick, no remarkable trend was observed in the crack pattern. However, it could be seen that from a 5\% addition of sugarcane bagasse ash, there is a reduction in the crack along the parallel block dimension of the compressed earth brick.

The African Regional Standards for Compressed Earth Blocks/Bricks (CEBs) as reported by [23] (p. 79) defines "CEBs as masonry elements which are small in size and which have regular and verified characteristics obtained by the static or dynamic compression of earth in a humid state followed by immediate demolding." The CEBs are composed of soil (earth), an additive as a stabilizer (Sugarcane Bagasse Ash used in this research), and water that are mechanically compressed. They are characterized by Texture; Geometry (Length, Width and Height that vary from region to region); Appearance; Cracks (Micro-cracks that can be tolerated on all faces and Macro-cracks that are conditionally accepted on all faces); Physicochemical (Pitting due to the swelling of expansive materials is not tolerated); Mechanical (Compressive, Abrasive, Tensile strengths, Shrinkage, Modulus of rupture and Density) and Hygrometric (Water absorption and Abrasion loss of matter) characteristics. The type of soil used, the amount and type of additive (stabilizer) used, and the technique of compression influences the above characteristics of CEBs [14] (pp. 60-66) and [16] (pp. 16-20). An additive is a substance added during manufacture of CEBs, so as to improve the final characteristics of the CEB or to enhance particular characteristics. In this research the target particular characteristics were compressive strength $\left(2.5 \mathrm{~N} / \mathrm{mm}^{2}\right)$ [21] and shrinkage cracking $(<0.5 \mathrm{~mm})$ [21] since the end CEB product was for low cost housing in Western Kenya, East African.

\section{Conclusions}

Based on the results obtained, the following conclusions can be drawn:

- The compressive strength of Sugarcane Bagasse Ash stabilized Compressed Earth Bricks increased with an increase in Sugarcane Bagasse Ash and was 65\% higher than the control with the addition of 10 Sugarcane Bagasse Ash. 
- The compressive strength of Sugarcane Bagasse Ash stabilized Compressed Earth Bricks increased with duration of curing. At 28 days, the control did not satisfy the requirement of KS02-1070 [21] while the 3\%, 5\%, 8\% and 10\% sugarcane bagasse stabilized Compressed Earth Bricks satisfied the minimum compressive strength requirement of the code.

- For the $10 \%$ Sugarcane Bagasse Ash stabilized compressed earth brick, the 14 to 21 day compressive strength growth rate was higher than the 21 to 28 day compressive strength growth rate, while for the control, 3\%, 5\% and 8\% Sugarcane Bagasse Ash stabilized compressed earth brick the 21 st to the 28 th day compressive strength growth rate was higher than the 14 to 21 day growth rate.

- Stabilized soil bricks exhibited a similar failure pattern to concrete's mode of failure while the unstabilized soil bricks in contrast disintegrated into smaller fragments.

- The stabilized and unstabilized Compressed Earth Bricks had crack width less than $0.3 \mathrm{~mm}$. The control sample and the $3 \%$ stabilized compressed earth brick had higher crack length along the parallel block dimension than the $5 \%$ and $8 \%$ and $10 \%$ stabilized compressed earth brick.

\section{Acknowledgments}

The authors would like to thank Tshwane University of Technology for funding this research.

\section{Author Contributions}

This research was designed by Ramadhan W. Salim, The analysis of Data was done by Ramadhan W. Salim, Julius M. Ndambuki and David A. Adedokun and the paper was jointly written by David A. Adedokun, Ramadhan W. Salim, and Julius M. Ndambuki.

\section{Conflicts of Interest}

The authors declare no conflict of interest.

\section{References}

1. Shitote, S.M.; Nyomboi, T.; Muumbo, A.; Wanjala, R.S.; Khadambi, E.L.; Orowe, J.; Sakwa, F.; Apollo, A. A Pre-Cast Concrete Technology for Affordable Housing in Kenya. In Proceedings of the International conference on Advances in Engineering and Technology, Entebbe, Uganda, 16-19 July 2006; Mwakali, J.A., Taban-Wani, G., Eds.; Elsevier: Entebbe, Uganda, 2006; pp. 680-695.

2. Wamukoya, M.B. An Investigation into the Suitability of Using Bagasse Ash in Stabilization of Soil Bricks; Moi University: Eldoret, Kenya, 2009.

3. Rigassi, V.; CRATerre-EAG. Compressed Earth Bricks: Manual of Production; Deutsches Zentrum für Entwicklungstechnologien-GATE: Eschborn, Germany, 1985; Volume 1, pp. 1-143.

4. Chan, C.-M.; Low, L.-P. Development of a Strength Prediction Model for "Green" Compressed Stabilised Earth bricks. J. Sustain. Dev. 2010, 3, 140-150.

5. Caterpillar. Introduction to Soil Stabilization; Caterpillar: Peoria, IL, USA, 2006; pp. 1-23.

6. United States Department of the Army. Army, Military Soils Engineering; United States Department of the Army: Washington, DC, USA, 1992; pp. 9.1-9.23. 
7. The Housing and Building Research Institute (HABRI). Stabilised Soil Blocks (SSBs): Manual Selection, Testing and Production of SSB; University of Nairobi, HABI: Nairobi, Kenya, 2003.

8. Republic of Kenya. National Report on the Review and Appraisal of the Implementation of the Habitat Agenda and the National Plan of Action on Shelter and Human Settlements to the (Istanbul +5); UN-Habitat: Istanbul, Turkey, 2000; pp. 1-143.

9. Faria, K.C.P.; Gurgel, R.F.; Holanda, J.N.F. Recycling of sugarcane bagasse ash waste in the production of clay bricks. J. Environ. Manag. 2012, 101, 7-12.

10. Onchieku, J.M.; Chikamai, B.N.; Rao, M.S. Optimum Parameters for the Formulation of Charcoal Briquettes Using Bagasse and Clay as Binder. Eur. J. Sustain. Dev. 2012, 1, 477-492.

11. Tantawy, M.A.; EL-Roudi, A.M.; Salem, A.A. Immobilization of Cr (VI) in bagasse ash blended cement pastes. Constr. Build. Mater. 2012, 30, 218-223.

12. Cordeiro, G.C.; Toledo Filho, R.D.; Tavares, L.M.; Fairbairn, E.M.R. Pozzolanic Activity and Filler Effect of Sugarcane Bagasse Ash in Portland Cement and Lime Mortars. Cem. Concr. Compos. 2008, 30, 410-418.

13. Keogh, B.T. Pozzolanic Products Produced from Bagasse Ash. U.S. Patent 4249954 A, 10 February 1981.

14. Srinivasan, R.; Sathiya, K. Experimental Study on Bagasse Ash in Concrete. Int. J. Serv. Learn. Eng. 2010, 5, 60-66.

15. Ganesan, K.; Rajagopal, K.; Thangave, K. Evaluation of Bagasse Ash as Supplementary Cementitious Material. Cem. Concr. Compos. 2007, 29, 515-524.

16. Onyelowe, K.C. Cement Stabilized Akwuete Lateritic Soil and the Use of Bagasse Ash as Admixture. Int. J. Sci. Eng. Invest. 2012, 1, 16-20.

17. Alavez-Ramirez, R.; Montes-Garcia, P.; Martinez-Reyes, J.; Altamirano-Juarez, D.C.; Gochi-Ponce, Y. The Use of Sugarcane Bagasse Ash and Lime to Improve the Durability and Mechanical Properties of Compacted Soil Blocks. Constr. Build. Mater. 2012, 34, 296-305.

18. Khan, M.J.; Qasim, M. Integrated Use of Boiler Ash as Organic Fertilizer and Soil Conditioner with NPK in Calcareous Soil. Songklanakarin J. Sci. Technol. 2008, 30, 281-289.

19. British Standard Institution. BS 1377-2:1990-Method of the Test for Soils for Civil Engineering Purposes. Classification tests. In BS 1377; British Standards Institution (BSI): London, UK, 1990.

20. American Concrete Institute. State-of-the-Art Report on Soil-Cement; American Concrete Institute (ACI): Detroit, MI, USA, 1992.

21. Kenya Bureau of Standards. KS02-1070, Kenya Standard Specification for Stabilized Soil Block; Kenya Bureau of Standards (KBS): Nairobi, Kenya, 1993.

22. American Society for Testing and Materials. ASTM Standard D2487. In Standard Practice for Classification of Soils for Engineering Purposes (Unified Soil Classification System); ASTM International: West Conshohocken, PA, USA, 2011.

23. Adam, E.A.; Agib, A.R.A. Compressed Stabilised Earth Block Manufacture in Sudan; United Nations Educational, Scientific and Cultural Organization: Paris, France, 2001.

2014 by the authors; licensee MDPI, Basel, Switzerland. This article is an open access article distributed under the terms and conditions of the Creative Commons Attribution license (http://creativecommons.org/licenses/by/3.0/) 